\title{
EFEITO DE PÓS DE ORIGEM VEGETAL E DE TERRA DIATOMÁCEA SOBRE ASPECTOS DA BIOLOGIA DE ZABROTES SUBFASCIATUS (BOH., 1833) EM FEIJÃO ARMAZENADO
}

\section{E.S. Souza; E.L.L. Baldin}

Universidade Estadual Paulista, Faculdade de Ciências Agronômicas, Departamento de Produção Vegetal Defesa Fitossanitária, Rua José Barbosa de Barros, 1780, CEP 18610-307, Botucatu, SP, Brasil. E-mail: efrain@fca.unesp.br

\section{RESUMO}

O presente trabalho teve por objetivo avaliar o efeito de pós provenientes de 4 espécies vegetais e de terra diatomácea, em diferentes concentrações, impregnados a grãos de feijoeiro, sobre a oviposição e alguns parâmetros biológicos de Zabrotes subfasciatus (Boheman, 1833) (Coleoptera: Chrysomelidae: Bruchinae) criados em feijão, Phaseolus vulgaris, variedade IAC-Carioca sob condições de laboratório $\left(\mathrm{T}=25 \pm 2^{\circ} \mathrm{C}\right.$, U.R. $=70 \pm 10 \%$ e fotofase de $12 \mathrm{~h}$ ). Foi realizado um experimento em esquema fatorial, utilizando-se os tratamentos tipos de pós (quatro pós vegetais, pó de diatomácea e a testemunha) e concentrações $(0,1 \%, 0,5 \%, 1,0 \%, 2,0 \%$ e 3,0\%), em delineamento inteiramente casualizado, com 10 repetições. Cinco casais do bruquíneo foram colocados no interior de recipientes plásticos contendo $10 \mathrm{~g}$ de grãos do feijão impregnados com as diferentes concentrações dos pós. Avaliaram-se os seguintes parâmetros biológicos: oviposição, viabilidade larval, número e peso de adultos emergidos. A interação dos diferentes pós com as concentrações foi significativa para todos os parâmetros avaliados, indicando que o aumento da concentração eleva a eficiência dos materiais contra o bruquíneo. Os tratamentos à base de pó de folhas deMentha pulegium L. e de terra diatomácea apresentaram as maiores eficiências, seguidos pelo pó de folhas + ramos + inflorescência de Chenopodium ambrosioides L. e de folhas de Ruta graveolens L.; o pó de sementes de Azadirachta indica A. Juss. revelou os menores índices de eficiência no controle alternativo de Z. subfasciatus.

PALAVRAS-CHAVE: Phaseolus vulgaris, bruquíneo-do-feijão, plantas inseticidas, pós.

\section{ABSTRACT}

EFFECT OF VEGETABLE POWDERS AND DIATOMACEOUS EARTH ON BIOLOGICAL ASPECTS OF ZABROTES SUBFASCIATUS (BOH., 1833) IN STORED BEANS. The objective of this work was to evaluate the effect of powders from 4 plant species and diatomaceous earth, indifferent concentrations and mixed with stored beans, on the oviposition and some biological parameters of Zabrotes subfasciatus (Boheman, 1833) (Coleoptera: Chrysomelidae: Bruchinae) raised on beans, Phaseolus vulgaris, variety IAC-Carioca, under laboratory conditions $\left(\mathrm{T}=25^{\circ} \mathrm{C} \pm 2, \mathrm{RH}=70 \pm 10 \%\right.$; and photoperiod $=12 \mathrm{~h}$ ). An experiment in factorial design was conducted, the treatments being powders (4 vegetable, diatomaceous earth an control) and concentrations $(0.1 \%, 0.5 \%, 1.0 \%, 2.0 \%$ and $3.0 \%$ ) in a completely randomized design, with 10 replicates. Five pairs of the bruchin were placed within plastic containers, containing $10 \mathrm{~g}$ of IAC-Carioca beans impregnated with the different concentrations of the powders. The following biological parameters were evaluated: oviposition, larval viability, and number and weight of emerged adults. The interaction of different powders with the concentrations was significant for all parameters evaluated, indicating that increased concentration increases the efficiency of the materials against the insect. The treatments with powders of leaves from Mentha pulegium L.and diatomaceous earth presented the highest efficiencies, followed by leaves + branches + inflorescence from Chenopodiumambrosioides L. and leaves from Ruta graveolens L.; the powder of seeds of Azadirachta indica A. Juss. revealed the lowest efficiency in the control of Z. subfasciatus.

KEY WORDS: Phaseolus vulgaris, mexican bean weevil, botanical insecticides, powders.

\section{INTRODUÇÃO}

O Brasil está entre os maiores produtores e consumidores mundiais de feijão, Phaseolus vulgaris L., considerado importante fonte protéica na dieta dos brasileiros (Oliveira et al., 1979; Gualberto, 1981). Entretanto, durante o armazenamento dos grãos, o país sofre muitas perdas, sendo uma das causas o 
ataque de bruquíneos, principalmente Zabrotes subfasciatus (Boheman, 1833) (Coleoptera: Chrysomelidae: Bruchinae). Originário do Novo Mundo, é considerado uma das principais pragas do feijão armazenado nas Américas Central e do Sul, África, Mediterrâneo e Índia (Oliveira; Vendramim, 1999), tendo sido introduzido em muitos países da Europa por meio de feijões infestados, onde tem ocasionalmente ampliado seus danos para outros legumes (MeIK; Dobie, 1986).

As perdas de grãos de feijoeiro causadas por esse caruncho chegam a 35\% no México, América Central ePanamá evariam de7\% a 15\% no Brasil(ScHOONHOvEN; CARdona, 1982). Nas regiões Sudeste e Sul do Brasil, as perdas chegam a $20 \%$ (WIENDL, 1975) e no Nordeste a $40 \%$ (Oliveira et al., 1977).

Entre os principais danos provocados por $Z$. subfasciatus destacam-se a perda de peso e alterações físicas, além da redução do poder germinativo e nutritivo dos grãos, comprometendo seu valor comercial (FERREIRA, 1960; GALlo et al., 2002). Somam-se, ainda, os danos indiretos, relacionados à entrada de micro-organismos e ácaros e o aquecimento da massa de grãos (Magalhães; Carvalho, 1988; Rosolem; Marubayashi, 1994).

O controle dessa praga é realizado tradicionalmente por meio de inseticidas químicos, que oferecem risco de contaminação ao aplicador e ao consumidor, devido aos resíduos potencialmente tóxicos deixados por esses produtos que muitas vezes são aplicados próximo ao período de consumo (Golob; KILMINSTER, 1982; Schoonhoven; DAN, 1982). Rego et al. (1986) ressaltaram aspectos relacionados ao perigo de se consumir os grãos logo após o emprego desses produtos, pela eventual presença de resíduos tóxicos, o que pode acentuar o desenvolvimento de doenças crônicas não-transmissíveis.

Formas alternativas de controle de pragas vêm sendo estudadas nas últimas três décadas visando oferecer elementos/táticas menos agressivos à saúde humana e ao meio ambiente, com a valorização de plantas que possuam substâncias com propriedades inseticidas. Nesse sentido, alguns países como Brasil, México, Equador e Chile têm desenvolvido pesquisas buscando, em plantas nativas e exóticas, compostos químicos com potencial para o controle de pragas agrícolas, também conhecidos comoinseticidas botânicos (Arruda; Batista, 1998; Rodríguez, 2000; MazzonetTo; Vendramim, 2003).

Os produtos de origem vegetal são utilizados na forma de pós, extratos ou óleos que, em geral, são inócuos para os aplicadores e consumidores, e podem provocar mortalidade, repelência, inibição da oviposição, além de comprometer o desenvolvimento dos insetos. (WeAver et al., 1994). Dessa forma, constituem uma alternativa aos inseticidas químicos sin- téticos, principalmente pela sua eficiência, facilidade de aplicação e obtenção, rápida degradação e baixa toxicidade para os aplicadores (FARONI et al., 1995; TAluKder; Howse, 1995; Oliveira; Vendramim, 1999; SousA et al., 2005), adequando-se aos programas de manejo integrado de pragas.

Além dos produtos provenientes de plantas, a terra diatomácea também vem sendo empregada no controle de pragas durante o armazenamento. Tratase de um pó inerte, proveniente de algas diatomáceas fossilizadas, que possui o dióxido de sílica como principal ingrediente. A sílica tem a capacidade de desidratar os insetos, causando a morte em um período variável de um a sete dias, dependendo da espécie-praga. É considerada uma prática segura para operadores e consumidores dos grãos, com ação inseticida duradoura, pois não perde efeito ao longo do tempo (LORINI et al., 2001).

Assim, o presente trabalho teve por objetivo avaliar os possíveis efeitos de pós de diferentes espécies vegetais e de terra diatomácea, utilizados em diferentes concentrações, sobre a biologia de Z. subfasciatus em grãos de feijão armazenado.

\section{MATERIAL E MÉTODOS}

O trabalho foi conduzido no Laboratório de Resistência de Plantas a Insetos e Plantas Inseticidas (LARESPI) da FCA/UNESP, Campus de Botucatu, SP, Brasil (22 $53^{\prime} 09^{\prime \prime} S, 48^{\circ} 26^{\prime} 42^{\prime \prime} \mathrm{W}$ e $804 \mathrm{~m}$ de altitude) durante2007.Paraarealizaçãodosensaiosfoimantida uma criação estoque de Z. subfasciatus já existente no laboratório, no interior de uma câmara climatizada ( $\mathrm{T}$ $=25 \pm 2^{\circ} \mathrm{C}$; U.R. $=70 \pm 10 \%$ e fotofase $=12 \mathrm{~h}$ ). Foram utilizados frascos de vidro de um litro, fechados com tampa rosqueável, onde foi efetuada uma abertura circular, adaptando-se uma tela de nylon com malha fina para permitir a aeração interna e evitar a fuga dos bruquídeos. Cada frasco recebeu $0,3 \mathrm{~kg}$ de grãos de feijão IAC-Carioca recém-colhidos, sendo infestados com, aproximadamente, 300 adultos de Z. subfasciatus não sexados. Foi escolhida essa variedade defeijão, por proporcionarumbom desenvolvimentoaobruquíneo.

Foram preparados seis tratamentos, todos à base de pó, a partir das seguintes estruturas: sementes de nim (Azadirachta indica A. Juss.), folhas + ramos de poejo (Mentha pulegium L.), folhas + ramos de arruda (Ruta graveolens L.), folhas + ramos + inflorescência de erva-de-Santa Maria (ESM) (Chenopodiumambrosioides L.), pó de terra diatomácea (TD) (Insecto ${ }^{\circledR}$ ) e testemunha (sem pó). As estruturas vegetais foram coletadas um mês antes dos ensaios no Departamento de Horticultura do próprio Campus e secas em estufa a $40^{\circ} \mathrm{C}$ por 48 horas, sendo posteriormente trituradas em moinho de facas, para a obtenção dos respectivos 
pós, conforme metodologia citada por Oliveira; VENDRAMIM (1999). Os pós foram conservados em frascos escuros hermeticamente fechados para terem suas propriedades conservadas, sendo abertos somente no momento do uso.

Foram realizadas 10 repetições por tratamento, sendo cada parcela considerada uma repetição. As parcelas constituíram-se cada uma, de $10 \mathrm{~g}$ de grãos do genótipo IAC-Carioca, juntamente com o respectivo pó, nas concentrações de $0,1 \%, 0,5 \%, 1,0 \%, 2,0 \%$ e $3,0 \%$. Foram utilizados recipientes plásticos $(4,0 \times 5,0$ $\mathrm{cm}$ ) hermeticamente vedados. O experimento foi instalado em delineamento inteiramente casualizado num esquema fatorial, com os fatores pós/estruturas (6 níveis) e concentrações (5 níveis). Após o preparo das parcelas, foram liberados 5 casais adultos de $Z$. subfasciatus (48h de idade) no interior de cada recipiente, sendo estes mantidos nas mesmas condições da criação estoque.

Os insetos foram removidos dos frascos 7 dias após a infestação. Passados 20 dias após a liberação dos adultos, foi contabilizado o número de ovos viáveis e inviáveis por parcela. E, passados mais 7 dias, ou seja, 27 dias da infestação inicial, as parcelas passaram a ser avaliadas diariamente para determinar a porcentagem de viabilidade larval (relação entre quantidade de ovos viáveis e número de adultos emergidos), o número de adultos emergidos e o peso dos adultos recém-emergidos. Para a pesagem, foi usada uma placa de Petri ( $2 \mathrm{~cm}$ de diâmetro) tarada, onde os insetos recém-emergidos eram acondicionados vivos e pesados em uma balança analítica de precisão, modelo Marte AL $(0,0001)$.

Os resultados obtidos foram submetidos à análise de variância pelo Teste $\mathrm{F}$, sendo as médias comparadas pelo teste de Tukey ao nível de $5 \%$ de probabilidade, utilizando-se o programa ESTAT 2.0 (UNESP de Jaboticabal, SP). Previamente os dados foram normalizados pela análise de Bonferroni.

\section{RESULTADOS E DISCUSSÃO}

A média de ovos depositados por Z. subfasciatus nos grãos de feijão IAC-Carioca contendo pós de nim, poejo, arruda e erva-de-Santa Maria a 0,1\% não diferiu da observada na testemunha; já a média dos grãos impregnados com terra diatomácea foi significativamente inferior. O mesmo comportamento dos materiais foi observado quando se aumentou a concentração para $0,5 \%$. Na concentração de $1 \%$, os tratamentos à base de poejo e terra diatomácea apresentaram média de ovos significativamente inferiores à da testemunha. Nas dosagens de 2 e $3 \%$, foi constatado que todos os tratamentos reduziram a oviposição em relação à testemunha, exceção ao tratamento com nim, na concentração de 3\% (Tabela 1).

A interação entre os diferentes tipos de pós e concentrações foi significativa $\left(F=4,35^{*} ; \mathrm{p} \leq 0,05\right)$ para todos os tratamentos, revelando que o aumento da concentração reduz a oviposição do caruncho (Tabela 1). Para os tratamentos à base de nim, poejo e arruda, a oviposição decresceu de forma mais acentuada em relação à concentração mínima $(0,1 \%)$ a partir da concentração de $1 \%$. Já para os tratamentos com erva-de-Santa Maria e terra diatomácea, essa redução revelou-se a partir da concentração de $2 \%$ com esses pós. Essa queda na oviposição à medida que as concentrações foram elevadas, sugere a volatilização de compostos indesejáveis às fêmeas do caruncho pelos pós-vegetais, indicando um efeito deterrente. Já nos tratamentos com terra diatomácea, acredita-se que a redução na oviposição, está diretamente relacionada com a desidratação dos insetos e do ambiente interno do recipiente, o que também ocasionou uma alta mortalidade (Tabela 4). Outro fato que pode explicar a redução na oviposição, é a presença e a quantidade das partículas dos pós impregnados nos grãos o que, de certa forma, inibem ou fazem com que as fêmeas discriminem esses grãos.

Tabela 1 - Número médio ( $\pm \mathrm{EP})$ de ovos deZ. subfasciatus em grãos de feijão com vários pós em diferentes concentrações.

\begin{tabular}{llllrr}
\hline Pós & \multicolumn{5}{c}{ Concentrações } \\
\cline { 2 - 6 } & \multicolumn{1}{c}{$0,1 \%$} & \multicolumn{1}{c}{$0,5 \%$} & $1,0 \%$ & $2,0 \%$ & $3,0 \%$ \\
\hline Nim & $82,4 \pm 6,6 \mathrm{aA}$ & $82,6 \pm 5,7 \mathrm{aA}$ & $59,6 \pm 5,8 \mathrm{abAB}$ & $45,6 \pm 11,4 \mathrm{bB}$ & $49,8 \pm 8,8 \mathrm{abB}$ \\
Poejo & $96,2 \pm 17,0 \mathrm{aA}$ & $57,4 \pm 12,7 \mathrm{aAB}$ & $30,8 \pm 7,7 \mathrm{bcB}$ & $3,4 \pm 1,3 \mathrm{cC}$ & $4,4 \pm 1,7 \mathrm{cC}$ \\
Arruda & $81,8 \pm 25,5 \mathrm{abA}$ & $70,4 \pm 9,5 \mathrm{aA}$ & $58,8 \pm 6,5 \mathrm{abB}$ & $33,8 \pm 5,5 \mathrm{bB}$ & $34,4 \pm 6,4 \mathrm{bB}$ \\
ESM & $95,6 \pm 5,6 \mathrm{aA}$ & $77,8 \pm 8,9 \mathrm{aA}$ & $62,2 \pm 7,4 \mathrm{abA}$ & $27,0 \pm 5,7 \mathrm{bB}$ & $6,8 \pm 1,1 \mathrm{cB}$ \\
TD & $41,6 \pm 5,6 \mathrm{bA}$ & $24,4 \pm 7,0 \mathrm{~b} \mathrm{~B}$ & $15,2 \pm 6,4 \mathrm{cBC}$ & $2,2 \pm 1,3 \mathrm{cD}$ & $1,0 \pm 0,6 \mathrm{cD}$ \\
Test. $^{1}$ & $92,8 \pm 4,0 \mathrm{aA}$ & $95,8 \pm 8,5 \mathrm{aA}$ & $97,0 \pm 12,7 \mathrm{aA}$ & $106,4 \pm 8,4 \mathrm{aA}$ & $85,6 \pm 6,3 \mathrm{aA}$ \\
\hline
\end{tabular}

Médias seguidas pela mesma letra minúscula na vertical e maiúscula na horizontal não diferem entre si pelo teste de Tukey ( $\mathrm{p} \leq 0,05)$; $\mathrm{CV}=21,33 \%$.

Dados originais: para análise foram transformados em $(x+0,5)^{1 / 2}$.

${ }^{1}$ Para cada concentração foram preparadas testemunhas (sem pó). 
A terra diatomácea mostrou-se efetiva na redução da oviposição de Z. subfasciatus em todas as concentrações, junto com poejo a partir de $2 \%$ e erva-de-SantaMaria a partir de 3\%. Tal eficácia da terra diatomácea certamente relaciona-se com a redução da umidade gerada no ambiente e/ou pela desidratação do inseto pela cutícula ao entrar em contato com o produto, conforme citado por Ebeling (1971) e KorUnic (1998).

Em trabalho de BARBOSA et al. (2002), baixas taxas de oviposição de bruquíneos foram constatadas nos tratamentos que envolveram o uso do óleo de sementes de $A$. indica, confirmando uma maior toxidade do óleo em relação ao pó da semente, que neste trabalho possibilitou elevados índices de oviposição.

Quanto à viabilidade dos ovos do bruquíneo (Tabela 2), notou-se que quando utilizada a concentração mínima $(0,1 \%)$, somente os grãos tratados com terra diatomácea reduziram significativamente o índice, indicando um potencial ovicida, provavelmente relacionado à desidratação dos ovos aderidos aos grãos, mesmo em baixas concentrações. Já os demais tratamentos não diferiram da testemunha. Nas concentrações de $0,5 \%$ e $1,0 \%$ os tratamentos com terra diatomácea e poejo diferiram da testemunha, apresentando as menores médias de viabilidade dos ovos. A 2,0\% todos os tratamentos diferiram da testemunha, e a 3,0\% somente o tratamento com nim não diferiu da testemunha, gerando dúvidas sobre o efeito ovicida do pó de semente desse vegetal. Constatou-se também que quanto maior as concentrações dos pós, maior o número de ovos inviáveis. Além disso, notouse que a concentração de $2,0 \%$ da terra diatomácea reduziu a viabilidade dos ovos próximo a zero.

A interação entre diferentes tipos de pós e concentrações foi significativa $\left(F=3,32^{*} ; \mathrm{p} \leq 0,05\right)$ para todos os tratamentos, mostrando maior redução na viabilidade dos ovos conforme as concentrações dos pós foram aumentando (Tabela 2). Para o tratamento com poejo, a viabilidade foi significativamente reduzida em relação à concentração mínima $(0,1 \%)$ a partir da dose de $0,5 \%$. Nos tratamentos com nim, erva-deSanta-Maria e terra diatomácea a redução na viabilidade ocorreu a partir de 2,0\%. Já no tratamento com arruda, somente a 3,0\% foi possível observar uma redução significativa na viabilidade dos ovos comparativamente à dosagem mínima $(0,1 \%)$.

No geral, os resultados de viabilidade dos ovos tratados com os pós são próximos aos obtidos por outros autores, comoGUZMÁN-MALDONADO et al.(1996) e BARBosa et al. (2002), que avaliaram o efeito de diversas espécies vegetais sobre a oviposição de $Z$. subfasciatus.

A presença dos pós a $0,1 \%$ e $0,5 \%$ não afetou a viabilidade larval do bruquíneo nos grãos de feijoeiro (Tabela 3). Isso poderia sugerir que, ao penetrarem no interior dos grãos, as larvas fiquem protegidas de uma possível ação larvicida dos pós. Entretanto, quando a concentraçõessubiu para 1,0\%,observou-sereduçãona viabilidade larval obtida no tratamento com erva-deSanta Maria. Tal fato pode estar relacionado com a presença de compostos volatilizados por essa espécie e que podem ter inibido ou reduzido a alimentação das larvas, retardandoe/ou diminuindo, consequentemente, a emergência de adultos dos grãos. O mesmo comportamentofoiobservadoa 2,0\%, comos tratamentos erva-deSanta Maria, poejo eterra diatomácea, quenestaconcentração diferiram da testemunha. Com relação à terra diatomácea, pode ser que a redução da viabilidade larval tenha ocorridoem virtude da redução deumidade dentro dos frascos e, consequentemente dos grãos, tornando-osimprópriosaodesenvolvimentolarval.Quanto ao tratamento à base de nim, não foi detectada diferença estatística em relação à testemunha em nenhuma concentração (Tabela 3), indicando que o pó das sementes dessa espécievegetalnãoafeta odesenvolvimentolarval de Z. subfasciatus.

Tabela 2 - Número médio ( \pm EP) de ovos viáveis de Z. subfasciatus em grãos de feijão com vários pós em diferentes concentrações.

\begin{tabular}{llccrr}
\hline Pós & \multicolumn{5}{c}{ Concentrações } \\
\cline { 2 - 6 } & \multicolumn{1}{c}{$0,1 \%$} & \multicolumn{1}{c}{$0,5 \%$} & $1,0 \%$ & $2,0 \%$ & $3,0 \%$ \\
\hline Nim & $56,8 \pm 4,7 \mathrm{abAB}$ & $65,0 \pm 6,9 \mathrm{aA}$ & $39,0 \pm 4,8 \mathrm{ab} \mathrm{AB}$ & $31,0 \pm 9,8 \mathrm{bB}$ & $29,4 \pm 5,3 \mathrm{aB}$ \\
Poejo & $66,6 \pm 13,2 \mathrm{abA}$ & $28,2 \pm 8,2 \mathrm{bcB}$ & $12,4 \pm 2,8 \mathrm{cBC}$ & $1,8 \pm 1,1 \mathrm{cdC}$ & $1,4 \pm 1,1 \mathrm{bC}$ \\
Arruda & $53,4 \pm 17,8 \mathrm{abA}$ & $48,6 \pm 5,9 \mathrm{abA}$ & $31,2 \pm 4,9 \mathrm{abAB}$ & $21,4 \pm 3,4 \mathrm{bAB}$ & $12,2 \pm 3,3 \mathrm{bB}$ \\
ESM & $69,4 \pm 5,2 \mathrm{aA}$ & $47,4 \pm 6,4 \mathrm{abA}$ & $38,0 \pm 6,3 \mathrm{abAB}$ & $16,4 \pm 4,5 \mathrm{bcBC}$ & $4,4 \pm 1,4 \mathrm{bC}$ \\
TD & $27,4 \pm 3,6 \mathrm{bA}$ & $14,0 \pm 4,8 \mathrm{cAB}$ & $9,2 \pm 4,2 \mathrm{cABC}$ & $0,8 \pm 0,5 \mathrm{dBC}$ & $0,0 \pm 0,0 \mathrm{bC}$ \\
Test. $^{1}$ & $71,0 \pm 3,0 \mathrm{aA}$ & $72,2 \pm 4,3 \mathrm{aA}$ & $70,0 \pm 6,3 \mathrm{aA}$ & $74,8 \pm 6,9 \mathrm{aA}$ & $60,4 \pm 4,2 \mathrm{aA}$ \\
\hline
\end{tabular}

Médias seguidas pela mesma letra minúscula na vertical e maiúscula na horizontal não diferem entre si pelo teste de Tukey ( $\mathrm{p} \leq$ 0,05); $\mathrm{CV}=28,52 \%$.

Dados originais: para análise foram transformados em arcosen $(x+0,5)^{1 / 2}$.

${ }^{1}$ Para cada concentração foram preparadas testemunhas (sem pó). 
Tabela 3 - Porcentagem média de viabilidade larval média ( \pm EP) de Z. subfasciatus em grãos de feijão com vários pós em diferentes concentrações.

\begin{tabular}{llllrr}
\hline Pós & \multicolumn{5}{c}{ Concentrações } \\
\cline { 2 - 6 } & \multicolumn{1}{c}{$0,1 \%$} & \multicolumn{1}{c}{$0,5 \%$} & $1,0 \%$ & $2,0 \%$ & $3,0 \%$ \\
\hline Nim & $64,2 \pm 4,4 \mathrm{aA}$ & $59,7 \pm 2,6 \mathrm{aA}$ & $35,1 \pm 5,4 \mathrm{abA}$ & $44,0 \pm 7,1 \mathrm{aA}$ & $40,3 \pm 3,9 \mathrm{abA}$ \\
Poejo & $60,1 \pm 2,7 \mathrm{aA}$ & $44,4 \pm 6,2 \mathrm{aA}$ & $37,7 \pm 6,5 \mathrm{abA}$ & $0,0 \pm 0,0 \mathrm{bB}$ & $0,0 \pm 0,0 \mathrm{cB}$ \\
Arruda & $48,8 \pm 12,6 \mathrm{aA}$ & $44,1 \pm 3,9 \mathrm{aA}$ & $29,1 \pm 3,1 \mathrm{aB}$ & $48,7 \pm 6,5 \mathrm{aA}$ & $32,8 \pm 11,2 \mathrm{bA}$ \\
ESM & $60,3 \pm 3,3 \mathrm{aA}$ & $48,9 \pm 8,5 \mathrm{aAB}$ & $27,5 \pm 7,6 \mathrm{bBC}$ & $11,7 \pm 7,5 \mathrm{bCD}$ & $8,8 \pm 8,8 \mathrm{cD}$ \\
TD & $53,1 \pm 7,7 \mathrm{aA}$ & $37,1 \pm 3,2 \mathrm{aA}$ & $39,5 \pm 12,8 \mathrm{abA}$ & $6,6 \pm 6,6 \mathrm{bB}$ & $0,0 \pm 0,0 \mathrm{cC}$ \\
Test. $^{1}$ & $65,9 \pm 2,4 \mathrm{aA}$ & $67,6 \pm 3,1 \mathrm{aA}$ & $65,6 \pm 3,7 \mathrm{aA}$ & $70,9 \pm 6,3 \mathrm{aA}$ & $66,5 \pm 4,6 \mathrm{aA}$ \\
\hline
\end{tabular}

Médias seguidas pela mesma letra minúscula na vertical e maiúscula na horizontal não diferem entre si pelo teste de Tukey ( $\mathrm{p} \leq 0,05) ; \mathrm{CV}=27,14 \%$.

Dados originais: para análise foram transformados em arcosen $(x+0,5)^{1 / 2}$.

${ }^{1}$ Para cada concentração foram preparadas testemunhas (sem pó).

Ainteraçãoentrediferentestiposdepóseconcentrações foi significativa $\left(\mathrm{F}=5,27^{*} ; \mathrm{p} \leq 0,05\right)$ para esse parâmetro (Tabela 3) em todos os tratamentos, exceto para o nim. Assim, observou-se que o tratamento com poejo reduziu a viabilidade larval a zero, quando utilizadoa 2,0\%, diferindo significativamente da concentração mínima (0,1\%). O tratamento com arruda (a 1\%) também reduziu a viabilidade, porém essa eficiência é questionável, uma vez que nas concentrações 2 e $3 \%$ a viabilidade tornou a se elevar. Já a erva-de-Santa Maria apresentou-seeficientena redução da viabilidadelarval a partir da concentração de $1 \%$ e a terra diatomácea a partirde2,0\%,em relaçãoà concentração mínima $(0,1 \%)$.

Considerando a biologia de Z. subfasciatus, as larvas não entraram em contato direto com as partículas dos pós vegetais, uma vez que os ovos desse inseto ficam aderidos aos grãos e as larvas de primeiro ínstar penetram rapidamente através de seu tegumento, sem caminhar entre os grãos. Isso sugere que a ação de pósvegetais sobre as larvas desse bruquíneo ocorra de maneira indireta, não matando as larvas por contato, mas por inibição alimentar decorrente dos odores volatilizadosnointerior dosfrascos. Apesar também da baixa viabilidadenos tratamentos com terra diatomácea, o mesmo fato não pode ser associado, acreditando-se que nes se tratamento as larvas não chegaram a eclodir devido a desidratação prévia dos ovos. Porém, faz-se necessário um estudo mais detalhado sobre essa hipótese, utilizando-se outras espécies de bruquíneos para comparação, como Acanthoscelides obtectus (Coleoptera: Chrysomelidae Bruchinae), cujos ovos ficam soltos entre os grãos (CREDLAND;DENDY, 1992). Assim, poderia ser comprovada a ação larvicida dos pós testados. Em experimentos utilizando pó de erva-de-Santa Maria para o controlenatural de Sitophilus zeamais (Coleoptera: Curculionidae) em milho armazenado, Delobel; MAlonga (1987), Rodríguez;SÁnches (1994) e Silva etal. (2003) relataram valores de viabilidade larval correspondentes a $0,5 \%, 3,7 \%$ e $0 \%$, respectivamente, comprovando o efeito inseticida desse vegetal.

Tabela 4 - Número médio ( \pm EP) de adultos deZ. subfasciatus emergidos em grãos de feijão com vários pós em diferentes concentrações.

\begin{tabular}{llccrr}
\hline Pós & \multicolumn{5}{c}{ Concentrações } \\
\cline { 2 - 6 } & \multicolumn{1}{c}{$0,1 \%$} & $0,5 \%$ & $1,0 \%$ & $2,0 \%$ & $3,0 \%$ \\
\hline Nim & $36,2 \pm 2,9 \mathrm{aA}$ & $39,6 \pm 5,8 \mathrm{abA}$ & $16,2 \pm 3,4 \mathrm{abAB}$ & $14,4 \pm 5,2 \mathrm{bB}$ & $11,8 \pm 2,3 \mathrm{bB}$ \\
Poejo & $40,2 \pm 8,6 \mathrm{aA}$ & $13,2 \pm 5,0 \mathrm{cdB}$ & $4,8 \pm 1,4 \mathrm{cBC}$ & $0,0 \pm 0,0 \mathrm{cC}$ & $0,0 \pm 0,0 \mathrm{cC}$ \\
Arruda & $31,2 \pm 9,2 \mathrm{abA}$ & $20,8 \pm 1,8 \mathrm{bAB}$ & $9,0 \pm 1,7 \mathrm{bcBC}$ & $10,4 \pm 2,2 \mathrm{bABC}$ & $3,8 \pm 1,3 \mathrm{bcC}$ \\
ESM & $41,4 \pm 2,0 \mathrm{aA}$ & $22,8 \pm 5,4 \mathrm{bAB}$ & $11,4 \pm 2,9 \mathrm{bcBC}$ & $3,2 \pm 0,5 \mathrm{bcCD}$ & $0,8 \pm 0,8 \mathrm{cD}$ \\
TD & $14,8 \pm 3,3 \mathrm{bA}$ & $5,2 \pm 1,6 \mathrm{dAB}$ & $4,4 \pm 1,9 \mathrm{cAB}$ & $0,2 \pm 0,2 \mathrm{cB}$ & $0,0 \pm 0,0 \mathrm{cB}$ \\
Test. $^{1}$ & $46,6 \pm 1,5 \mathrm{aA}$ & $48,6 \pm 2,7 \mathrm{aA}$ & $46,4 \pm 5,7 \mathrm{aA}$ & $53,4 \pm 7,4 \mathrm{aA}$ & $40,6 \pm 4,5 \mathrm{aA}$ \\
\hline
\end{tabular}

Médias seguidas pela mesma letra minúscula na vertical e maiúscula na horizontal não diferem entre si pelo teste de Tukey ( $\mathrm{p} \leq 0,05) ; \mathrm{CV}=29,04 \%$.

Dados originais: para análise foram transformados em $(x+0,5)^{1 / 2}$.

${ }^{1}$ Para cada concentração foram preparadas testemunhas (sem pó). 
Os dados relacionados ao número de adultos emergidos dos grãos (Tabela 4) mostraram que, na concentração mínima $(0,1 \%)$, somente o tratamento com terra diatomácea diferiu da testemunha, com a menor média de adultos. Na concentração de $0,5 \%$, todos os tratamentos, com exceção do nim, diferiram da testemunha mostrando-se eficientes na redução da emergência do bruquíneo. Já nas concentrações de $1,0 \%, 2,0 \%$ e 3,0\% todos os tratamentos (exceção ao nim, a $1 \%$ ) diferiram da testemunha, reduzindo progressivamente a emergência dos adultos, conforme o aumento da concentração dos pós. Observou-se também que, em concentração de $2,0 \%$, a emergência de adultos nos tratamentos com poejo e terra diatomácea cessou.

A interação dos fatores pós e concentrações afetou significativamente $\left(F=3,22^{*} ; \mathrm{p} \leq 0,05\right)$ a emergência de adultos deZ. subfasciatus em todos os tratamentos, sendo que o tratamento com poejo reduziu significativamente as médias a partir da concentração $0,5 \%$, comparativamente à concentração mínima. A 1,0\% os tratamentos com erva-deSanta Maria e arruda mostraram redução significativa na emergência quando comparados à concentração mínima, já os tratamentos com nim e terra diatomácea só diferiram da concentração $0,1 \%$, quando elevados a 2,0\% (Tabela 4).

Acredita-se que a variação quanto ao número de adultos emergidos na maioria dos tratamentos com pós vegetais esteja condicionada à deterrência na oviposição e possíveis efeitos antibióticos de compostos volatilizados sobre as larvas, que podem ter a alimentação inibida ocasionando a morte. Nos tratamentos com terra diatomácea, acredita-se que a causa da variação do número de adultos esteja relacionada com a desidratação dos ovos e/ou do ambiente, desfavorecendo a emergência de adultos.
A toxicidade do pó de estruturas vegetais de ervade-Santa Maria sobre pragas de milho armazenadojá foi comprovada por diversos autores, podendo-se citar SiLva et al. (2003) que obtiveram 100\% de mortalidade de $S$. zeamais utilizando uma concentração de 1,0\% (p/p) de pó dessa planta. Delobel; Malonga (1987), empregando uma concentração de 2,5\% (p/p), relataram $90 \%$ de mortalidade de Caryedon serratus (Coleoptera:Chrysomelidae: Bruchinae). Em grãos de feijoeiro, Mazzoneto; Vendramim (2003) e Procópio et al. (2003) obtiveram $100 \%$ de mortalidade deA.obtectus e Z. subfasciatus com a mesma espécie vegetal.

A forma como os pós-vegetais podem ter afetado o desenvolvimento de larvas de Z. subfasciatus não foi alvo de investigação na presente pesquisa, porém, acredita-se que isso possa ter ocorrido, uma vez que os grãos são permeáveis e trocam gases com o meio externo. Desta forma, determinados compostos voláteis tóxicos presentes nesses pós poderiam ter exercido algum tipo de ação (fumigante) sobre as larvas no interior dos grãos.

Os dados referentes ao peso médio de adultos (Tabela 5) provenientes de grãos tratados com os diferentes pós mostraram não haver diferença significativa entre os tratamentos a 0,1 e $0,5 \%$. A $1 \%$ somente o tratamento com terra diatomácea apresentou peso de insetos inferior à testemunha. $\mathrm{O}$ peso de adultos emergidos a 2,0 e3,0\% não foi observado, uma vezque não ocorreram emergências nos tratamentos à base de arruda e terra diatomácea nessas concentrações.

A interação foi significativa $\left(F=2,77^{*} ; p \leq 0,05\right)$ para os tratamentos com arruda, erva-de-Santa Maria e terra diatomácea, sendo que o tratamento com erva-de-Santa Maria diferiu estatisticamente da concentração mínima $(0,1 \%)$ a $0,5 \%$. Já os tratamentos com arruda e terra diatomácea diferiram a $1,0 \%$, apresentando as menores médias de peso de adultos (Tabela 5).

Tabela 5 - Peso médio (EP) em gramas de adultosZ. subfasciatus obtidos em grãos de feijão com vários pós em diferentes concentrações.

\begin{tabular}{llcr}
\hline Pós & \multicolumn{3}{c}{ Concentrações } \\
\cline { 2 - 4 } & \multicolumn{1}{c}{$0,1 \%$} & $0,5 \%$ & $1,0 \%$ \\
\hline Nim & $0,0021 \pm 0,00009 \mathrm{aA}$ & $0,0022 \pm 0,00008 \mathrm{aA}$ & $0,0022 \pm 0,00010 \mathrm{aA}$ \\
Poejo & $0,0023 \pm 0,00008 \mathrm{aA}$ & $0,0023 \pm 0,00014 \mathrm{aA}$ & $0,0023 \pm 0,00025 \mathrm{aA}$ \\
Arruda & $0,0021 \pm 0,00006 \mathrm{aAB}$ & $0,0023 \pm 0,00012 \mathrm{aA}$ & $0,0020 \pm 0,00010 \mathrm{aB}$ \\
ESM & $0,0024 \pm 0,00010 \mathrm{aAB}$ & $0,0022 \pm 0,00008 \mathrm{aB}$ & $0,0025 \pm 0,00021 \mathrm{aA}$ \\
TD & $0,0023 \pm 0,00012 \mathrm{aAB}$ & $0,0027 \pm 0,00021 \mathrm{aA}$ & $0,0018 \pm 0,00009 \mathrm{bB}$ \\
Test. $^{1}$ & $0,0026 \pm 0,00007 \mathrm{aA}$ & $0,0026 \pm 0,00007 \mathrm{aA}$ & $0,0026 \pm 0,00007 \mathrm{aA}$ \\
\hline
\end{tabular}

Médias seguidas pela mesma letra minúscula na vertical e maiúscula na horizontal não diferem entre si pelo teste de Tukey ( $\mathrm{p} \leq 0,05)$; $\mathrm{CV}=12,53 \%$.

${ }^{1}$ Para cada concentração foram preparadas testemunhas (sem pó). 


\section{CONCLUSÕES}

Os grãos impregnados com erva de Santa-Maria, poejo e arruda são deterrentes à oviposição de $Z$. subfasciatus.

A terra diatomácea possui elevada eficiência na inibição do desenvolvimento do bruquíneo quando confinado em ambientes vedados, uma vez que este material reduz a umidade interna e/ou desidrata o inseto e seus ovos.

Geralmente, em função da grande disponibilidade, facilidade de extração e principalmente pelo baixo custo de utilização, esses materiais podem ser apontados como alternativas viáveis no controle natural desse caruncho em armazéns, especialmente em pequenas propriedades.

Apesar dos efeitos tóxicos do nim serem frequentemente relatados sobre carunchos, o pó de sementes dessa meliácea mostrou atividade inseticida inferior neste trabalho, contrastando com expectativa inicial, onde se esperava a obtenção de melhores índices de controle com essa planta.

Em geral, o aumento da concentração dos pós vegetais e terra diatomácea elevou a eficiência no controle de Z. subfasciatus em grãos de feijão armazenado.

\section{AGRADECIMENTOS}

Os autores expressam seus agradecimentos ao Prof. Dr. José Vargas de Oliveira, da Universidade Federal Rural de Pernambuco (UFRPE), pelo fornecimento da terra diatomácea para a execução deste trabalho.

\section{REFERÊNCIAS}

ARRUDA, F.P.; BATISTA J.L. Efeito da luz, de óleos vegetais e de cultivares de caupi na infestação do caruncho Callosobruchus maculatus (Fabr., 1775) (Coleoptera: Bruchidae). Caatinga, v.11, p.53-57, 1998.

BARBOSA, F.R.; YOKOYAMA, M.; PEREIRA, P.A.A.; ZIMMERMANN, F.J.P. Controle do caruncho-dofeijoeiro Zabrotes subfasciatus com óleos vegetais, munha, materiais inertes e malathion. Pesquisa Agropecuária Brasileira, v.37, n.9, p.1213-1217, 2002.

CREDLAND, P.F.; DENDY, J. Intraespecific variation in bionomic characters of the Mexican bean weevil, Zabrotes subfasciatus. Entomologia Experimentalis et Applicata, v.65, p.39-47, 1992.

DELOBEL, A.; MALONGA, P. Insecticidal properties of six plant materials against Caryedon serratus (OL.) (Coleoptera: Bruchidae). Journal of Stored Prodcts Research, v.23, p.173-176, 1987.
EBELING, W. Sorptive dusts for pests control. Annual Review of Entomology, v.16, p.123-158, 1971.

FARONI, L.R.A.; MOLIN, L.; ANDRADE, E.T.; CARDO$\mathrm{SO}$, E.G. Utilização de produtos naturais no controle de Acanthoscelides obtectus em feijão armazenado. Revista Brasileira de Armazenamento, v.20, p.44-48, 1995.

FERREIRA, A.M. Subsídios para o estudo de uma praga do feijão (Zabrotes subfasciatus Boh. - Coleoptera, Bruchidae) dos climas tropicais. Garcia de Orta, v.8, n.3, p.559-581, 1960.

GALLO, D.; NAKANO, O.; SILVEIRA NETO, S.; CARVALHO, R.P.L.; DE BATISTA, G.C.; BERTI FILHO, E.; PARRA, J.R.P.; ZUCCHI, R.A.; ALVES, S.B.; VENDRAMIM, J.D.; MARCHINI, L.C.; LOPES, J.R.S.; OMOTO, C. Entomologia agrícola. Piracicaba: FEALQ, 920p. 2002.

GUALBERTO, D.G. Avaliação nutricional e sensorial de misturas de feijão (Phaseolus culgaris L.) e soja (Glicine max. L.) processadas por extrusão. 1981. 51p. Dissertação (Mestrado em Ciências e Tecnologia de Aliementos) Universidade Federal de Viçosa, Viçosa, 1981.

GOLOB, P.; KILMINSTER, A. The biology and control of Zabrotes subfasciatus (Boheman) (Coleoptera: Bruchidae) infesting red kidney beans. Journal of Stored Prodcts Research, v.18, p.95-101, 1982.

GUZMÁN-MALDONADO, H.; CASTELLANOS, J.Z.; MEJÍA, E.G. Relationship between theoretical and experimentally detected tannin content of common bean (Phaseolus vulgaris L.). Food Chemistry, v.55, n,4, p.333-335, 1996.

KORUNIC, Z. Review diatomaceous earths, a group of natural insecticides. Journal of Stored Products Research, v.34, n.2/3, p.87-97, 1998.

LORINI, I.; FERREIRA FILHO, A; BARBIERI, I.; DEMAMAM, N.A.; MARTINS, R.R.D. Terra de diatomáceas como alternativa no controle de pragas de milho armazenado em propriedade familiar. Agroecologia e Desenvolvimento Rural Sustentável, v.2, p.32-36, 2001.

MAGALHÃES, B.P.; CARVALHO, S.M. Insetos associados à cultura. In: ZIMMERMANN, M.J. DE O.; ROCHA, M.; YAMADA, T. (Ed.). Cultura do feijoeiro - fatores que afetam a produtividade. Piracicaba: Potafos, 1988. p.573-589.

MAZZONETO, F.; VENDRAMIM, J. Efeito de pós de origem vegetal sobre Acanthoscelides obtectus (Say) (Coleoptera:Bruchidae) em feijão armazenado. Neotropical Entomology, v.32, p.145-149, 2003

MEIK, J.; DOBIE, P. The ability of Zabrotes subfasciatus to attack cowpeas. Entomologia Experimentalis et Applicata, v.42, p.151-158, 1986. 
OLIVEIRA, A.M.; VENDRAMIM, J.D. Repelência de óleos essenciais e pós vegetais sobre adultos de Zabrotes subfasciatus (Boh.) (Coleoptera: Bruchidae) em sementes de feijoeiro. Anais da Sociedade Entomológica do Brasil, v.28, n.3, p.549-555, 1999.

OLIVEIRA, J.V.; RAMALHO, M.A.P.; BARBIN, D. Avaliação dos prejuízos em feijões Vigna sinensis (L.) Savi e Phaseolus vulgaris (L.) devido ao ataque de Zabrotes subfasciatus (Boh., 1833) (Coleoptera, Bruchidae). Ecossistema, v.2, p.19-22, 1977.

OLIVEIRA, A.M.; PACOVA, B.E.; SUDO, S.; ROCHA, A.C.M.; BARCELLOS, D.F. Incidência de Zabrotes subfasciatus Bohemann, 1853 e Acanthoscelides obtectus Say, 1831 em diversas cultivares de feijão armazenado (Col., Bruchidae). Anais da Sociedade Entomológica do Brasil, v.8, p.47-55, 1979.

PROCÓPIO, S.; VENDRAMIM, J.; RIBEIRO, J.; SANTOS, J. Efeito de pós vegetais sobre Acanthoscelides obtectus (SAY) e Zabrotes subfasciatus (BOH.) (Colepotera: Curculionidae). Revista Ceres, v.50, p.395-405, 2003.

REGO, A.F.M.; VEIGA, A.F.S.L.; RODRIGUES, Z.A.; OLIVEIRA, M.L.; REIS, D.V. Efeito da incidência de Zabrotes subfasciatus (Boheman, 1833) (Coleoptera: Bruchidae) sobre genótipos de Phaseolus vulgaris L. Anais da Sociedade Entomológica do Brasil, v.15, p.53-69, 1986.

RODRÍGUEZ, D.A.; SÁNCHEZ. S. Polvos vegetales para el combate de Sitophilus zeamais y Zabrotes subfasciatus en maíz y frijol. Turrialba, v.44, p.160-167, 1994.

RODRÍGUEZ, H.C. Plantas contra plagas: potencial práctico de ajo, anona, nim, chile e tabaco. Texcoco: Red de Acción sobre Plaguicidas y Alternativas en México (RAPAM), 2000. 133p.

ROSOLEM, C.A.; MARUBAYASHI, O.M. Seja o doutor do seu feijoeiro. Informações Agronomicas, Piracicaba, v.68, p.1-16, 1994. (Encarte especial) .
SCHOONHOVEN, A.V.; CARDONA, C. Low levels of resistance to the Mexican bean weevil in dry bean. Journal of Economic Entomology, v.76, n.4, p.567-569, 1982.

SCHOONHOVEN, A.V.; DAN, W.V. Control of Zabrotes subfasciatus (Boh.) (Coleoptera: Bruchidae) with seeds protectant fungicides. Journal of Stored Products Research, v.18, p.143-146, 1982.

SILVA, G.; LAGUNES, A.; RODRÍGUEZ, J.; RODRÍGUEZ, D. Evaluación de polvos vegetales solos y en mezcla con carbonato de calcio para el control de Sitophilus zeamais Motschulsky en maíz almacenado. Ciencia e Investigación Agraria, v.30, p.153-160, 2003.

SOUSA, A.H.; MARACAJÁ, P.B.; SILVA, R.M.A.; MOURA, A.M.N.; ANDRADE, W.G. Bioactivity of vegetal powders against Callosobruchus maculatus (Coleoptera: Bruchidae) in caupi bean and seed physiological analysis. Revista de Biologia e Ciências da Terra, v.5, p.5, 2005.

TALUKDER, F.A.; HOWSE, P.E. Evaluation of Aphanamixis polytachya as a source of repellents, antifeedants, toxicants and protectants in storage against Tribolium castaneum (Herbst). Journal of Stored Products Research, v.31, p.55-61, 1995.

WEAVER, D.K.; WELLS, C.D.; DUNKELL, F.V.; BERTSCH, W.; SING, S.E.; SHIHARAN, S. Insecticidal actitivy of floral, foliar, and root extracts of Tagetes minuta (Asterales: Asteraceae) against adult Mexican bean weevil (Coleoptera: Bruchidae). Journal of Economic Entomology, v.87, p.1718- 1725, 1994.

WIENDL, F.M. A desinfestação de grãos e produtos armazenados por meio de radiação ionizante. Piracicaba: CENA-USP, 1975. 26p. (Boletin de Divulgação 18).

Recebido em 11/4/08

Aceito em 13/5/09 